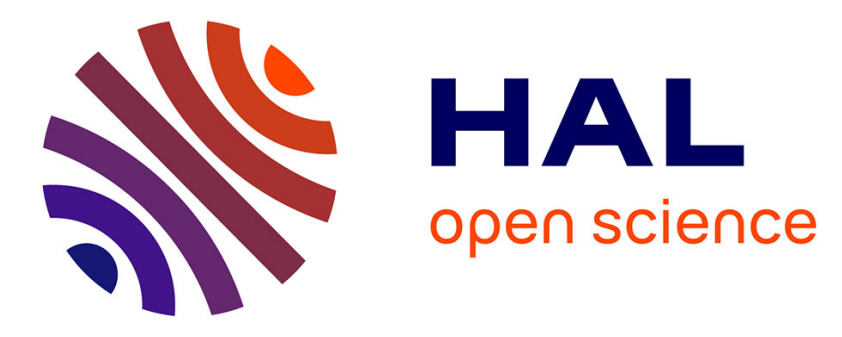

\title{
Measurement of magnetization using domain compressibility in CoFeB films with perpendicular anisotropy
}

N. Vernier, J-P Adam, S. Eimer, G. Agnus, T. Devolder, Thomas Hauet, B. Ocker, F. Garcia, D. Ravelosona

\section{To cite this version:}

N. Vernier, J-P Adam, S. Eimer, G. Agnus, T. Devolder, et al.. Measurement of magnetization using domain compressibility in CoFeB films with perpendicular anisotropy. Applied Physics Letters, 2014, 104 (12), pp.122404 10.1063/1.4869482 . hal-01282865

\section{HAL Id: hal-01282865 \\ https://hal.science/hal-01282865}

Submitted on 13 Jul 2016

HAL is a multi-disciplinary open access archive for the deposit and dissemination of scientific research documents, whether they are published or not. The documents may come from teaching and research institutions in France or abroad, or from public or private research centers.
L'archive ouverte pluridisciplinaire HAL, est destinée au dépôt et à la diffusion de documents scientifiques de niveau recherche, publiés ou non, émanant des établissements d'enseignement et de recherche français ou étrangers, des laboratoires publics ou privés. 


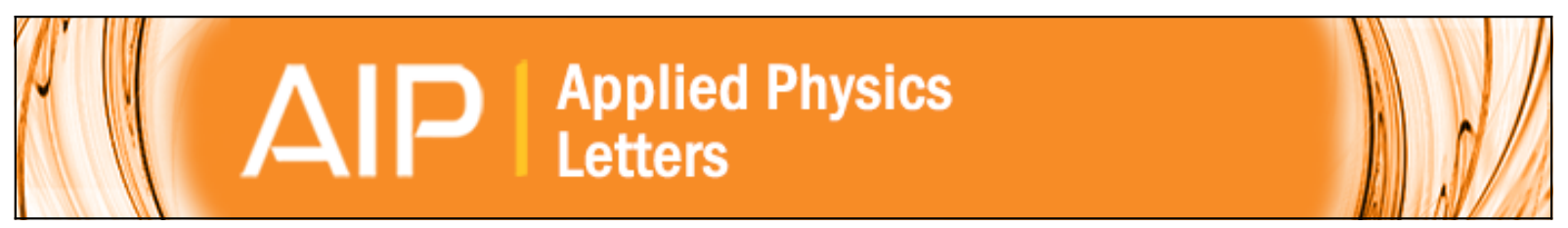

Measurement of magnetization using domain compressibility in CoFeB films with perpendicular anisotropy

N. Vernier, J.-P. Adam, S. Eimer, G. Agnus, T. Devolder, T. Hauet, B. Ocker, F. Garcia, and D. Ravelosona

Citation: Applied Physics Letters 104, 122404 (2014); doi: 10.1063/1.4869482

View online: http://dx.doi.org/10.1063/1.4869482

View Table of Contents: http://scitation.aip.org/content/aip/journal/apl/104/12?ver=pdfcov

Published by the AIP Publishing

\section{Articles you may be interested in}

Effect of Mg interlayer on perpendicular magnetic anisotropy of CoFeB films in $\mathrm{MgO} / \mathrm{Mg} / \mathrm{CoFeB} / \mathrm{Ta}$ structure Appl. Phys. Lett. 101, 122414 (2012); 10.1063/1.4754118

The study of perpendicular magnetic anisotropy in $\mathrm{CoFeB}$ sandwiched by $\mathrm{MgO}$ and tantalum layers using polarized neutron reflectometry

Appl. Phys. Lett. 100, 202406 (2012); 10.1063/1.4718423

Investigation of perpendicular magnetic anisotropy of CoFeB by $\mathrm{x}$-ray magnetic circular dichroism Appl. Phys. Lett. 100, 172414 (2012); 10.1063/1.4707380

Effect of thickness of $\mathrm{MgO}, \mathrm{Co}-\mathrm{Fe}-\mathrm{B}$, and Ta layers on perpendicular magnetic anisotropy of [Ta/Co60Fe20B20/MgO]5 multilayered films

J. Appl. Phys. 111, 07C111 (2012); 10.1063/1.3673408

Strong perpendicular magnetic anisotropy in thick CoFeB films sandwiched by $\mathrm{Pd}$ and $\mathrm{MgO}$ layers Appl. Phys. Lett. 96, 042503 (2010); 10.1063/1.3299009

\section{AlP Re-register for Table of Content Alerts}




\title{
Measurement of magnetization using domain compressibility in CoFeB films with perpendicular anisotropy
}

\author{
N. Vernier, ${ }^{1,2, a)}$ J.-P. Adam, ${ }^{1,2}$ S. Eimer, ${ }^{1,2}$ G. Agnus, ${ }^{1,2}$ T. Devolder,,${ }^{1,2}$ T. Hauet, ${ }^{3}$ B. Ocker, ${ }^{4}$ \\ F. Garcia, ${ }^{1,2}$ and D. Ravelosona ${ }^{1,2}$ \\ ${ }^{1}$ Université Paris-Sud, 91405 Orsay, France \\ ${ }^{2}$ Institut d'Electronique Fondamentale, CNRS, UMR 8622, Orsay, France \\ ${ }^{3}$ Institut Jean Lamour, CNRS - Universite de Lorraine, Boulevard des aiguillettes BP 70239, \\ F-54506 Vandoeuvre le's Nancy, France \\ ${ }^{4}$ Singulus technology AG, Hanauer Landstrasse 103, 63796 Kahl am Main, Germany
}

(Received 27 June 2013; accepted 13 March 2014; published online 24 March 2014)

\begin{abstract}
We present a method to map the saturation magnetization of soft ultrathin films with perpendicular anisotropy, and we illustrate it to assess the compositional dependence of the magnetization of $\mathrm{CoFeB}(1 \mathrm{~nm}) / \mathrm{MgO}$ films. The method relies on the measurement of the dipolar repulsion of parallel domain walls that define a linear domain. The film magnetization is linked to the field compressibility of the domain. The method also yields the minimal distance between two walls before their merging, which sets a practical limit to the storage density in spintronic devices using domain walls as storage entities. (C) 2014 AIP Publishing LLC. [http://dx.doi.org/10.1063/1.4869482]
\end{abstract}

Recently, there has been a renewed interest in spintronic devices relying on the motion of narrow domain walls in magnetic nanowires. This includes the use of domain walls as storage units ${ }^{1-3}$ or as information vectors performing logic operations. ${ }^{4,5}$ Since they combine a high perpendicular anisotropy $^{6}$ with a coercivity ${ }^{7}$ lower than the standard systems exhibiting perpendicular magnetic anisotropy (PMA), ultrathin $\mathrm{CoFeB} / \mathrm{MgO}$ films are a promising system to study the motion of narrow domain walls. Indeed, walls in $\mathrm{CoFeB} / \mathrm{MgO}$ systems are mobile ${ }^{7}$ in fields as low as $0.1 \mathrm{mT}$, and their motion seems not to be influenced by pinning phenomena for fields above $1 \mathrm{mT}$.

To fine tune the properties of such films, one can play with the Boron content, ${ }^{8}$ the Fe-to-Co composition, ${ }^{7}$ the degree of crystallization, 9,10 or the degree of mixing at the interfaces. ${ }^{11}$ A key feature to compare the performance of these films is their saturation magnetization Ms and its uniformity at the local scale. Conventional magnetometry methods like Superconducting Quantum Interference Device (SQUID) or vibrating sample magnetometers (VSMs) can inherently only give the spatial average of the magnetization and are prone to errors due to the parasitic magnetic signals coming from the substrate or the surface contamination. Methods based on torques or their field derivatives like ferromagnetic resonance (FMR) cannot separate the contributions of PMA and demagnetization fields in the thin film geometry, and they only give a qualitative measurement of the sample inhomogeneity. ${ }^{12}$

Here, we present a flexible method to measure the magnetization of soft PMA films that is operative down to sizes less than $100 \times 100 \mu \mathrm{m}^{2}$, and we illustrate it to assess the compositional dependence of $\mathrm{Ms}$ of $\mathrm{CoFeB} / \mathrm{MgO}$ films in both as-grown and annealed states. The method builds on Bauer's work ${ }^{13}$ and relies on the manipulation of two neighboring narrow domain walls. ${ }^{14-17}$ The principle is the following. Dipolar interactions favor the (central) domain

a)nicolas.vernier@u-psud.fr between the two walls, because the walls repel each other proportionally to the film magnetization. The walls' separation can be adjusted by an external field. The measurement of the field induced compressibility of the central domain by magneto-optical microscopy yields a calibration-free way of deriving the saturation magnetization and its spatial uniformity at the $10 \mu \mathrm{m}$ scale.

We have studied the compositions $\mathrm{Co}_{60} \mathrm{Fe}_{20} \mathrm{~B}_{20}$, $\mathrm{Co}_{40} \mathrm{Fe}_{40} \mathrm{~B}_{20}$, and $\mathrm{Co}_{20} \mathrm{Fe}_{60} \mathrm{~B}_{20}$, with the layer of interest being part of substrate $/ \mathrm{Ta}(5 \mathrm{~nm}) / \mathrm{CoFeB}(\mathrm{t}=1 \mathrm{~nm}) / \mathrm{MgO}$ $(2 \mathrm{~nm}) / \mathrm{Ta}(5 \mathrm{~nm})$ multilayers. Each sample was studied before and after an annealing of $2 \mathrm{~h}$ at $300^{\circ} \mathrm{C}$.

The magnetic configurations were probed using a polar Kerr imaging setup, with a $50 \times$ magnification lens of numerical aperture 0.35 . The nominal resolution according to Rayleigh criteria is $\delta=0: 8 \mu \mathrm{m}$. In practice we shall look at linear domain walls (Fig. 1), such that when there is a single domain wall its position $\mathrm{x}_{0}$ can be identified with an accuracy much better than $\delta$, by simply fitting the optical profile with a step function of slope $\delta$. Experimentally, several step functions having a progressive transition appeared suitable, here, we have used $\mathrm{f}(\mathrm{x})=\mathrm{K} \tan ^{-1}\left(\left(\mathrm{x}-\mathrm{x}_{0}\right) / \delta\right)$. When several parallel domain walls are present, the finding of their positions is done using a deconvolution procedure which requires the exact knowledge of the contrast between the upward and downward magnetized states. In practice, one thus needs to correct for the non-uniformity of the lightning and for the finite Faraday rotation of the objective lens. To cancel these artefacts, we have used the following experimental procedure.

The first step is to prepare a ribbon-like domain, the two limiting parallel walls are at positions $\mathrm{x}_{1}$ and $\mathrm{x}_{4}$ and are assumed to be far away from each other as compared to the domain wall width (i.e., $\left|\mathrm{x}_{4}-\mathrm{x}_{1}\right| \gg \delta$ ). To create the required type of domains, we have implemented the following sequence: the sample was first saturated using a negative field. Then, a short pulse of positive field nucleated several small domains. A subsequent small positive magnetic field was applied until the nucleated domains have almost 

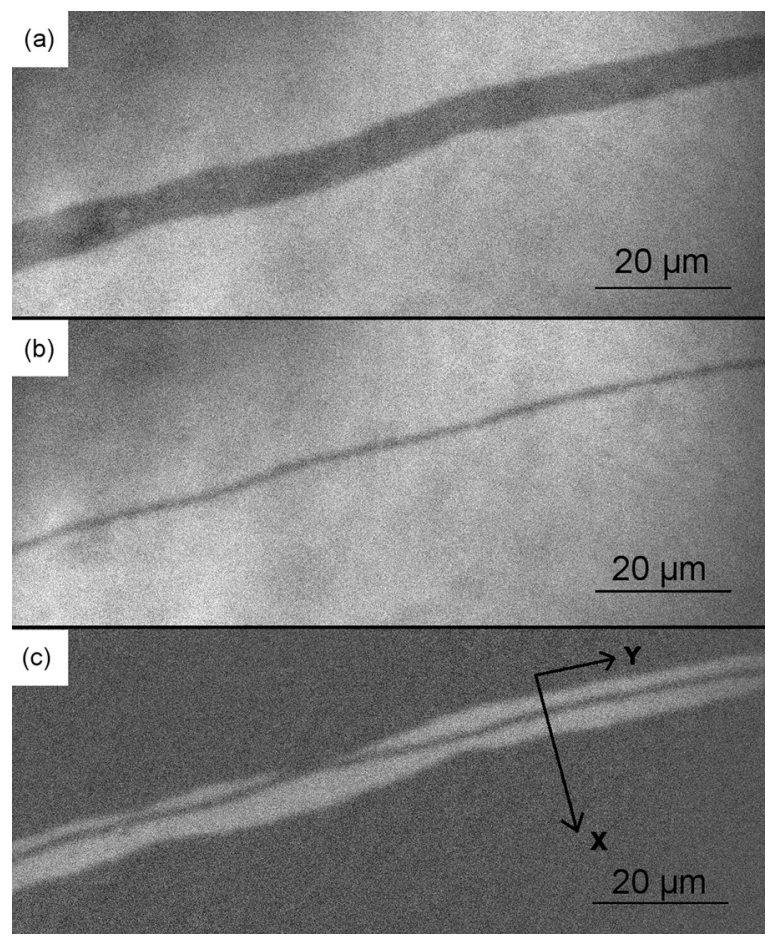

FIG. 1. Magneto-optical micrographs $\left(110 \times 45 \mu \mathrm{m}^{2}\right)$ of domain patterns in $\mathrm{Co}_{20} \mathrm{Fe}_{60} \mathrm{~B}_{20}(1 \mathrm{~nm}) / \mathrm{MgO}$ films. (a) Pair of well separated $(\mathrm{d} \approx 6 \mu \mathrm{m})$ domain walls at remanence. (b) Same pair of walls under a field of $0.59 \mathrm{mT}$. (c) Picture obtained by subtracting the two previous images.

coalesced. Because of the dipolar repulsion between two opposite domain walls, their merging in low field is prevented. It results in narrow ribbon-like unreversed domains at the frontier of two reversed domains. The idea is to use the compressibility of this ribbon-like domain. At last, to get a reference, the ribbon-like domain is expanded by applying a negative field for several seconds (Fig. 1(a)). Second, we apply an external field to compress the central domain (Fig. 1(b)). The walls are now positioned at $x_{2}$ and $x_{3}$. To estimate the new domain width $\mathrm{d}=\left|\mathrm{x}_{3}-\mathrm{x}_{2}\right|$, we subtract Fig. 1(a) from Fig. 1(b), getting Fig. 1(c). A stripe cut through $\mathrm{x}$ (see Fig. 1(c)) yields a contrast profile (Fig. 2) with plateaus accounting for the signals of a full reversal. The width of the stripe cut is chosen to mitigate the noise. In

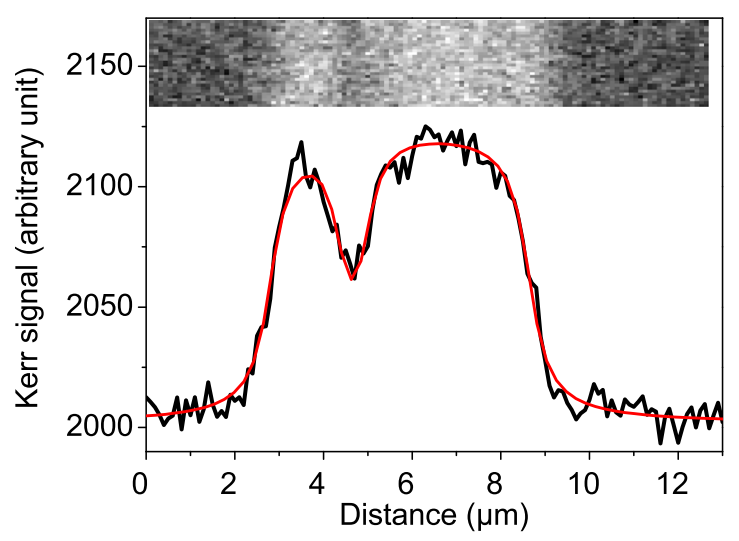

FIG. 2. Profile of the magneto-optical contrast obtained on the annealed $\mathrm{Co}_{20} \mathrm{Fe}_{60} \mathrm{~B}_{20}(1 \mathrm{~nm})$ sample, in a field of $0.59 \mathrm{mT}$. The walls positions found using Eq. (1) are $x_{1}=2: 89, x_{2}=4: 50, x_{3}=5: 09$, and $x_{4}=8: 89 \mu \mathrm{m}$. The wall-to-wall separation is thus $\mathrm{d}=590 \mathrm{~nm}$. Inset: magneto-optical image $\left(12: 2 \times 3.1 \mu \mathrm{m}^{2}\right)$ used to get the contrast profile. the example of Fig. 2, the central domain is narrower than the optical resolution (i.e., $\mathrm{d}<\delta$ ), such that the corresponding negative peak at $\mathrm{x}=5 \mu \mathrm{m}$ in the contrast profile does not reach the lower plateau. To get $\mathrm{d}=\left|\mathrm{x}_{3}-\mathrm{x}_{2}\right|$, one fits the contrast profile (Fig. 2) with a function

$$
c(x)=A_{0}+A_{0} \sum_{i=1}^{4}(-1)^{i} \arctan \frac{x_{i}-x}{\delta} .
$$

The adjustable parameters are the four wall positions $\mathrm{x}_{\mathrm{i}}$, the optical resolution $\delta$, the contrast scale $\mathrm{A}_{1}$, and an offset $\mathrm{A}_{0}$. We estimate that central domain size is known with an accuracy of $\pm 25 \mathrm{~nm}$. This number was certified with specially designed samples consisting of thin aluminum wires on silicon with variable widths ranging from 100 to $1000 \mathrm{~nm}$. Finally, we emphasize that the measurement procedure is repeated at various positions along the domain until a statistically reliable estimate of the dependence of $d$ with $\mathrm{H}_{\mathrm{ext}}$ is obtained (Fig. 3). This minimizes the uncertainty associated to the wall roughness that is generally observed and results from pinning effects. Indeed, defects can stop locally a domain wall and one can get a width bigger than the equilibrium one when the magnetic field $\mathrm{B}$ is monotonically increasing as a function of time. However, the pinning is not strong, and a slight increase of field enables to override most of the pinning defects. The results are slight fluctuations of the central domain width (see Figure 1) and a non zero propagation field (see below).

Let us now use the field dependence of the size of the central domain to get the film magnetization. If the domain wall width $\Delta$ is much smaller than the distance between the two walls, the wall-wall interaction is purely of dipolar origin and it is repulsive. ${ }^{13,14,18,19}$ Here, we shall consider wallto-wall distances greater than $300 \mathrm{~nm}$ (see Fig. 3) in high PMA systems ${ }^{7}$ where we expect $\Delta \leq 30 \mathrm{~nm}$, such that this condition is fulfilled. Under that approximation, the repulsive force is the analog of the Laplace force between two wires each carrying a charge current $\mathrm{I}=2 \mathrm{t} \mathrm{M}_{\mathrm{S}}$ and placed at separation d. ${ }^{20}$ On a given wall, the dipolar force per unit length is thus $\mu_{0} I^{2} /(2 \pi d)$. The film finite thickness term (see Ref. 19) can be neglected in our case because our wall separation is substantially larger. An additional term exits in case. However, in the presence of an external field, there is

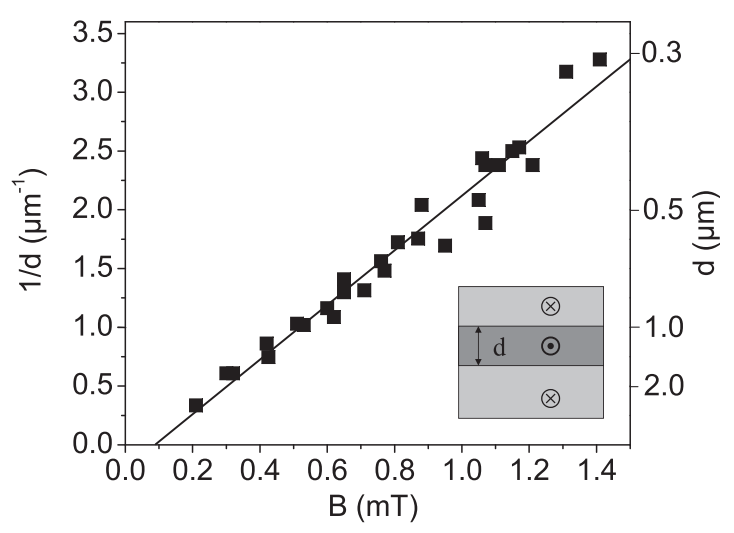

FIG. 3. Dependence of the wall to wall distance with the applied field for the as-grown $\mathrm{Co}_{20} \mathrm{Fe}_{60} \mathrm{~B}_{20}$ sample. The slope is the compressibility of the central wall, which measures the inverse magnetization. Inset: sketch of the domain structure. 
TABLE I. Synthesis of the results obtained on the different samples. "a" stands for as-grown (amorphous) samples. "c" stands for annealed (crystalline) samples. The sample a- $\mathrm{Co}_{60} \mathrm{Fe}_{20} \mathrm{~B}_{20}$ is not presented here because it was an in-plane anisotropy sample. The first set of SQUID measurements was incomplete, only two samples could be checked. So, a second run has been done, we took advantage of it to check again the first two samples.

\begin{tabular}{|c|c|c|c|c|c|}
\hline Sample & $\mathrm{a}-\mathrm{Co}_{20} \mathrm{Fe}_{60} \mathrm{~B}_{20}$ & $\mathrm{c}-\mathrm{Co}_{20} \mathrm{Fe}_{60} \mathrm{~B}_{20}$ & $\mathrm{a}-\mathrm{Co}_{40} \mathrm{Fe}_{40} \mathrm{~B}_{20}$ & $\mathrm{c}-\mathrm{Co}_{40} \mathrm{Fe}_{40} \mathrm{~B}_{20}$ & $\mathrm{c}-\mathrm{Co}_{60} \mathrm{Fe}_{20} \mathrm{~B}_{20}$ \\
\hline$\mu_{0} \mathrm{M}_{\mathrm{S}}(\mathrm{T})$ (SQUID 1st and 2nd measurement) & 1.38 & 1.5 and 1.41 & 1.26 & 1.38 & 0.9 and 1.1 \\
\hline$\mu_{0} \mathrm{M}_{\mathrm{S}}(\mathrm{T})(\mathrm{AGFM})$ & 1.3 & 1.1 & 1.15 & 1.3 & 0.8 \\
\hline$\mu_{0} \mathrm{M}_{\mathrm{S}}(\mathrm{T})$ (average of the above values) & 1.34 & 1.34 & 1.20 & 1.34 & 0.93 \\
\hline$\mu_{0} \mathrm{M}_{\mathrm{S}}(\mathrm{T})$ (present method) & 1.35 & 1.5 & 1.25 & 1.65 & 0.825 \\
\hline Critical destruction field (mT) & 1.3 & 2.2 & 1.7 & 2.9 & 0.6 \\
\hline Minimal wall to wall distance $d_{\min }$ & $355 \mathrm{~nm}$ & $220 \mathrm{~nm}$ & $260 \mathrm{~nm}$ & $185 \mathrm{~nm}$ & $470 \mathrm{~nm}$ \\
\hline
\end{tabular}

an additional Zeeman pressure tending to compress the central domain. This force per unit length is $-2 \mu_{0} \mathrm{M}_{\mathrm{s}} \mathrm{H}_{\text {ext }}$. In a defect free sample, these two forces would cancel each other when $\mathrm{tM}_{\mathrm{S}}=\pi \mathrm{dH}_{\mathrm{ext}}$. However, in real films, a finite propagation field $\mu_{0} \mathrm{H}_{\mathrm{P}} \approx 0.1 \mathrm{mT}$ is needed to overcome pinning effects and to induce domain wall motion. As a result there is a hysteresis in $\mathrm{d}$ as a function of the sweeping direction of the external field. Assuming the distance to be measured with a field compressing the central domain, the wall to wall distance $\mathrm{d}$ is

$$
d^{-1}=\pi \frac{H_{e x t}-H_{p}}{t M_{s}}
$$

Linear fits of $\mathrm{d}^{-1}$ as a function of $\mathrm{H}_{\text {ext }}$ (according to Eq. (2)) is very good, as shown in Fig. 3. The slope identifies to $\pi / \mathrm{tM}$, from which one gets $\mathrm{M}_{\mathrm{S}}$. The error bars on Ms can be roughly estimated from the extreme possibilities for the slope of the straight line and from the error bars on each point $( \pm 10 \mu \mathrm{T}$ for the external field, $\pm 25 \mathrm{~nm}$ for the width of the central domain). From this, we can guarantee that the relative error on the final result for Ms cannot be more than $10 \%$.

Table I gathers the magnetizations independently obtained using either our present method or conventional magnetometry on larger samples (at least $2 \times 2 \mathrm{~mm}^{2}$ ), on the various compositions of $\mathrm{CoFeB}$. The values are given before and after annealing except for the as-grown $\mathrm{Co}_{60} \mathrm{Fe}_{20} \mathrm{~B}_{20}$ sample because it showed in-plane easy axis. A satisfactory agreement is found between the magnetization values deduced from SQUID, AGFM, and domain compressibility. We attribute the die to die dispersion of the $M_{S} t$ values to the existence of composition and/or thickness fluctuations across the wafer, especially for the Co-rich compositions. These possible structural variations may exacerbate the inhomogeneity of the magnetization because of the proximity to the face-centered-cubic to hexagonal-compact phase boundary ${ }^{21}$ in the FeCo binary alloy phase diagram. In all cases, annealing slightly increases the magnetization, confirming the previous reports. ${ }^{22-24}$

The compositions leading to the highest magnetizations are $\mathrm{Co}_{20} \mathrm{Fe}_{60} \mathrm{~B}_{20}$ and $\mathrm{Co}_{40} \mathrm{Fe}_{40} \mathrm{~B}_{20}$. Position of ternary alloys on the Slater-Pauling curve is not obvious, ${ }^{25,26}$ but it seems that boron has little influence on the magnetic properties apart from a dilution effect. ${ }^{8}$ From the Slater-Pauling curve, a broad maximum of magnetization for a ratio of cobalt of around $28 \%$ is expected (corresponds to $35 \%$ for a
Boron-free CoFe alloy), which is compatible with our findings (Table I).

During these experiments, we have been able to measure two additional interesting quantities. The first quantity is the magnetic field needed to merge the two neighboring domain walls and let the central domain disappears abruptly. We emphasize that although two different configurations are expected depending on the winding directions of each wall, a unique critical field was measured: statistical measurements indicated that this critical field is a reproducible metric, reported in Table I. Let us note this measurement was carried out 3 or 4 times for each of the 5 samples, it was reproducible for each sample within the precision of the field scan which was $0.1 \mathrm{mT}$, and one can reject a lucky arbitrary behavior. Above these applied fields, the number of domain walls changes inside a given sample: the data integrity in domain wall based memories ${ }^{1}$ is then lost, which gives the working boundaries of such devices if based on soft PMA systems like ours. Besides, applying Eq. (2) at this critical destruction field yields the second interesting quantity: the minimal stable wall-to-wall distance, found between 180 and $500 \mathrm{~nm}$, depending on sample (Table I). The measurement of this minimum wall separation $d_{\text {min }}$ is interesting from both applied and fundamental points of view. Indeed $\mathrm{d}_{\text {min }}$ could be indicative of the effective profile of $180^{\circ}$ domain walls since the disappearance of the central domain may just occur when the two walls are about to start overlapping. Also, this minimal wall-to-wall distance $d_{\text {min }}$ sets a practical limit to the storage density in racetrack memory applications. ${ }^{1}$

In summary, we have presented a calibration-free method to measure the local magnetization in ultrathin magnetic film with perpendicular anisotropy. This technique allows site-specific measurements to be made, thus providing advantages for nanopatterned specimens, for which the sensitivity of conventional magnetometry methods is not sufficient. We have illustrated our method by studying the composition dependence of the magnetization of $\mathrm{CoFeB}$ ultrathin films. In addition, our method yields the minimal achievable stable distance between two domain walls in such soft films, which sets the storage density limit in memory paradigms based on domain walls.

The authors wish to thank Jean-Pierre Jamet and Jacques Ferré for useful discussions. This work was supported by the European Communities FP7 program through contract MAGWIRE number 257707. 
${ }^{1}$ S. S. P. Parkin, M. Hayashi, and L. Thomas, Science 320, 190 (2008).

${ }^{2}$ Y. Zhang, W. S. Zhao, D. Ravelosona, J.-O. Klein, J. V. Kim, and C. Chappert, J. Appl. Phys. 111, 093925 (2012).

${ }^{3}$ V. Uhlir, J. Vogel, N. Rougemaille, O. Fruchart, Z. Ishaque, V. Cros, J. Camarero, J. C. Cezar, F. Sirotti, and S. Pizzini, J. Phys.: Condens. Matter 24, 024213 (2012).

${ }^{4}$ D. A. Allwood, G. Xiong, C. C. Faulkner, D. Atkinson, D. Petit, and R. P. Cowburn, Science 309, 1688 (2005).

${ }^{5}$ J. Jaworowicz, N. Vernier, J. Ferre, A. Maziewski, D. Stanescu, D. Ravelosona, A. S. Jacqueline, C. Chappert, B. Rodmacq, and B. Dieny, Nanotechnology 20, 215401 (2009).

${ }^{6}$ S. Ikeda, K. Miura, H. Yamamoto, K. Mizunuma, H. D. Gan, M. Endo, S. Kanai, J. Hayakawa, F. Matsukura, and H. Ohno, Nat. Mater. 9, 721 (2010).

${ }^{7}$ C. Burrowes, N. Vernier, J.-P. Adam, L. Herrera Diez, K. Garcia, I. Barisic, G. Agnus, S. Eimer, Joo-Von Kim, T. Devolder, A. Lamperti, R. Mantovan, B. Ockert, E. E. Fullerton, and D. Ravelosona, Appl. Phys. Lett. 103, 182401 (2013).

${ }^{8}$ M. Munakata, S.-I. Aoqui, and M. Yagi, IEEE Trans. Mag. 41(10), 3262 (2005).

${ }^{9}$ Y. M. Lee, J. Hayakawa, S. Ikeda, F. Matsukura, and H. Ohno, Appl. Phys. Lett. 90, 212507 (2007).

${ }^{10}$ A. T. G. Pym, A. Lamperti, B. K. Tanner, T. Dimopoulos, M. Rührig, and J. Wecker, Appl. Phys. Lett. 88, 162505 (2006).

${ }^{11}$ T. Devolder, I. Barisic, S. Eimer, K. Garcia, J.-P. Adam, B. Ockert, and D. Ravelosona, J. Appl. Phys. 113, 203912 (2013).

${ }^{12}$ R. D. McMichael, M. D. Stiles, P. J. Chen, and J. W. F. Egelhoff, J. Appl. Phys. 83, 7037 (1998).
${ }^{13}$ M. Bauer, A. Mougin, J. P. Jamet, V. Repain, J. Ferré, R. L. Stamps, H. Bernas, and C. Chappert, Phys. Rev. Lett. 94, 207211 (2005).

${ }^{14}$ C. B. Muratov and V. V. Osipov, J. Appl. Phys. 104, 053908 (2008).

${ }^{15}$ A. Kubetzka, O. Pietzsch, M. Bode, and R. Wiesendanger, Phys. Rev. B 67, 020401 (2003).

${ }^{16}$ M. D. Mascaro, C. Nam, and C. A. Ross, Appl. Phys. Lett. 96, 162501 (2010).

${ }^{17}$ L. Thomas, M. Hayashi, R. Moriya, C. Rettner, and S. Parkin, Nature Commun. 3, 810 (2012).

${ }^{18}$ S. Wiebel, J.-P. Jamet, N. Vernier, A. Mougin, J. Ferré, V. Baltz, B. Rodmacq, and B. Dieny, J. Appl. Phys. 100, 043912 (2006).

${ }^{19}$ H.-B. Braun, Phys. Rev. B 50, 16485 (1994).

${ }^{20}$ E. M. Purcell, Electricity and Magnetism, Berkeley Physics Course Vol. 2 (McGraw-Hill book company, 1963), Chap. 10, paragraph 10.8.

${ }^{21}$ F. Schreiber, J. Pflaum, Z. Frait, T. Mhge, and J. Pelzl, Solid State Commun. 93, 965 (1995).

${ }^{22}$ D. D. Lam, F. Bonell, S. Miwa, Y. Shiota, K. Yakushiji, H. Kubota, A. F. T. Nozaki, S. Yuasa, and Y. Suzuki, J. Magn. 18, 5 (2013).

${ }^{23}$ M. Yamanouchi, A. Jander, P. Dhagat, S. Ikeda, F. Matsukura, and H. Ohno, IEEE Trans. Mag. Lett. 2, 3000304 (2011).

${ }^{24}$ C. Bilzer, T. Devolder, J.-V. Kim, G. Counil, C. Chappert, S. Cardoso, and P. P. Freitas, J. Appl. Phys. 100, 053903 (2006).

${ }^{25}$ I. Galanakis, P. Mavropoulos, and P. H. Dederichs, J. Phys. D: Appl. Phys. 39, 765 (2006).

${ }^{26}$ G. H. Fecher, H. C. Kandpal, S. Wurmehl, C. Felser, and G. Schönhense, J. Appl. Phys. 99, 08J106 (2006). 